\title{
Determination of polyurethane-grafted peptide (GSGREDVGSG) using bicinchoninic acid (BCA)
}

\section{assay}

\author{
Beata A Butruk-Raszeja ${ }^{1}$ \& Aleksandra Kuzminska ${ }^{1}$ \\ ${ }^{1}$ Laboratory of Biomedical Engineering, Faculty of Chemical \& Process Engineering, Warsaw University of \\ Technology, Warynskiego 1, 00-645 Warsaw, Poland
}

BioTechniques 64:245-253 (June 2018) 10.2144/btn-2018-0004

Keywords: BCA • peptide grafting • peptide quantification • polyurethane $\bullet$ REDV $\bullet$ surface modification $\bullet$ surface-bonded peptide 2018646

The goal in the presented study was to develop a simple, fast and accurate method for measuring the surface density of a short peptide sequence bound to a polymeric substrate. We analyzed polyurethane samples chemically modified with acrylic acid and polyurethane-grafted peptide (GSGREDVGSG) peptide and investigated the possibility of using the bicinchoninic acid (BCA) assay to determine surface density of the solid-supported peptide. We set the conditions (temperature, time) under which the test should be conducted. We also studied the interaction of the BCA reagent with polyurethane substrate and the effect of drying conditions as well as material type and form on the test response. We have proposed potential factors that might interfere with the BCA assay and chosen the proper control materials.

\section{Introduction}

The goal of the presented research was to develop a simple, fast and accurate method for measuring the surface density of a short peptide sequence bound to a polymeric substrate.

Estimating the surface density of a protein/peptide bound to the substrate is a difficult and demanding task. Methods proposed so far can be divided into those requiring the use of advanced and specialized equipment and those based on simple colorimetric tests. The first group of methods includes techniques such as XPS analysis and TOF-SIMS. More information on the use of these techniques in the analysis of solid-supported peptides can be found elsewhere [1,2].

One of the simpler methods based on colorimetric determination is measuring the concentration of sulfoNHS, which is released during peptide attachment. However, this method, as an indirect method, has a large measurement error. An interesting solution is the use of immunoenzymatic methods, including use of peptides conjugated with fluorochrome [3] or ELISA
$[4,5]$. The ELISA test is based on the use of monoclonal antibodies directed against the designated peptide. The huge advantage of the test is simultaneous information on the surface density and biological activity of the peptide being determined. Unfortunately, there is a high probability of nonspecific antibody-polymer interactions, which often overstate the obtained values or give falsepositive results even in the case of a control (peptide-free) material. During our research we met with the described problem, and it was not possible to eliminate it despite the use of various blockers (please refer to the Supporting Information for details).

Colorimetric assays are widely used to quantify proteins in solution and solid substrates due to their simplicity [3]. One of the commonly used tests is based on bicinchoninic acid (BCA) $[6,7]$. The BCA method eliminates difficulties of the Lowry method, making it easy to perform, with high sensitivity [8-11]. Briefly, the BCA assay is based on two reactions. First, amino acids form a complex with $\mathrm{Cu}^{+}$ions. In the next step, BCA creates a colored complex with the previously formed $\mathrm{Cu}^{+}$complex [12-14]. This reaction is temperature-dependent - the test is more sensitive at higher temperatures [9].

The BCA test offers the possibility to estimate the concentration of chemical substances containing peptide bond and/ or the following amino acids: cysteine, cystine, tyrosine and tryptophan. This assay has been successfully used in the determination of RGD on polycaprolactone substrates [6,12].

The aim of the presented study was to estimate the surface density of a ten-amino acid peptide (GSGREDVGSG) chemically linked to polyurethane (PU_. The REDV sequence has been shown to exhibit selectivity for selected cell types [15-18], so its use is highly desirable for biomaterials that induce a specific biological response from surrounding tissues.

We performed several microBCA assays to quantify the short peptide sequence grafted on the PU film. The PU film was modified with acrylic acid and short peptide sequence as described previously [19]. First, analysis of the BCA reagent interaction with PU susbstrates was carried out. The polymer substrates were prepared under different drying temperature and in different forms - 
in pellets, cut pellets, pellets with scraped outer surface, and PU film. This experiment allowed us to examine the interactions of the solid backround with the BCA reagent and whether the potential residual solvent in polymer film is important. After determining these interactions, we examined the surface density of PU-grafted peptide.

\section{Materials and methods}

Influence of BCA reaction conditions The reaction of analyzed peptide with BCA reagent has been performed under different incubation temperature (IT) and time $(\mathrm{T})$. The following variants were tested: $\mathrm{IT}=37^{\circ} \mathrm{C}, \mathrm{T}=2 \mathrm{~h} ; \mathrm{IT}=60^{\circ} \mathrm{C}, \mathrm{T}=0.5 \mathrm{~h}$; $\mathrm{IT}=60^{\circ} \mathrm{C}, \mathrm{T}=1 \mathrm{~h}$; and $\mathrm{IT}=60^{\circ} \mathrm{C}, \mathrm{T}=2 \mathrm{~h}$. BCA working solution was prepared according to the supplier protocol. The peptide solution was prepared by dissolving GSGREDVGSG (custom made, Novazym, Poznan, Poland) in the sodium phosphate buffer $(0.1 \mathrm{M}, \mathrm{pH}=8)$; concentrations of $0,0.5,5,10,20$ and $30 \mu \mathrm{g} / \mathrm{ml}$ were used. $150 \mu$ of the peptide solution was mixed with $150 \mu \mathrm{l}$ of BCA reagent and reacted in the dark under given IT and T. After the reaction, the sample was cooled down to room temperature and the absorbance at $562 \mathrm{~nm}$ was red. The standard curves were created by plotting net absorbance (calculated as a difference between the absorbance recorded for the sample and for the blank) versus total amount of peptide present in the sample. QuantiProBCA assay (Sigma-Aldrich, Poznan, Poland), which gives a linear response for peptide concentration from 0.5 to $30 \mu \mathrm{g} / \mathrm{ml}$, was used in all experiments.

Influence of polymer substrate In order to investigate the influence of polymer substrate on BCA reagent, two sets of materials were prepared and tested. The first set involved materials dried under different drying conditions. The PU foil was prepared as follows: ChronoFlex (AdvanSource Biomaterials, MA, USA) granules washed with $5 \%$ ethanol, dried to constant weight and dissolved in N,N-dimethylacetamide (DMAc, Sigma-Aldrich) to a final concentration of $20 \%(\mathrm{~W} / \mathrm{v})$. The solution was poured onto the clean glass and dried in the incubator at different temperatures (40, 70 and $100^{\circ} \mathrm{C}$ ) for $48 \mathrm{~h}$ under normal pressure. After the drying, part of the foil was subjected to an additional drying process under low pressure. The additional drying was performed in a freeze-dryer under the following parameters: pressure $0.1 \mathrm{mbar}$, temperature $40^{\circ} \mathrm{C}$, time $72 \mathrm{~h}$. After drying, round-shaped samples were cut off from the foil and contacted with BCA reagent $\left(1 \mathrm{~h}, 60^{\circ} \mathrm{C}\right)$.

The second set of materials differs in terms of sample type. Pristine, nonmodified PU was analyzed in the form of granules as received from the supplier. The following variants were tested: granules without any intervention (G), granules cut in half (CG), granules washed with pro-pan-2-ol (WG) and granules mechanically cleaned with scalpel (SG). Three different types of PUs were used: ChronoFlex, Elastolane and Estane. A given amount of granules (80 mg $\pm 6 \mathrm{mg}$ ) was contacted with BCA reagent $\left(1 \mathrm{~h}, 60^{\circ} \mathrm{C}\right)$ and the absorbance was measured according to the supplier protocol.

\section{Density of peptide chemically grafted to PU}

Pristine, non-modified PU (PU) and peptidegrafted PU (PU-REDV) were analyzed with BCA assay. Polymer samples were cut off from foil (the foil was prepared according to the description in 'The influence of drying conditions', under the following drying conditions: $40^{\circ} \mathrm{C}, 24 \mathrm{~h}$, normal pressure). Next, polymer samples were modified in a two-step reaction (Figure 1). In the first modification step, samples were coupled with spacer molecule (acrylic acid [AA]). Briefly, PU discs were immersed in a $2.3 \%$ solution of $\mathrm{HNO}_{3}$ in distilled water and heated to $35^{\circ} \mathrm{C}$. After reaching this temperature, ammonium cerium (IV) sulphate dihydrate $(0.1 \% \mathrm{w} / \mathrm{v})$ and $\mathrm{AA}(5 \% \mathrm{v} / \mathrm{v})$ were added to the solution. The mixture was left covered and stirred continuously for $1.5 \mathrm{~h}$. After that time, discs were washed with $0.1 \%$ sodium dodecyl sulfate (SDS) solution and rinsed three times with distilled water.

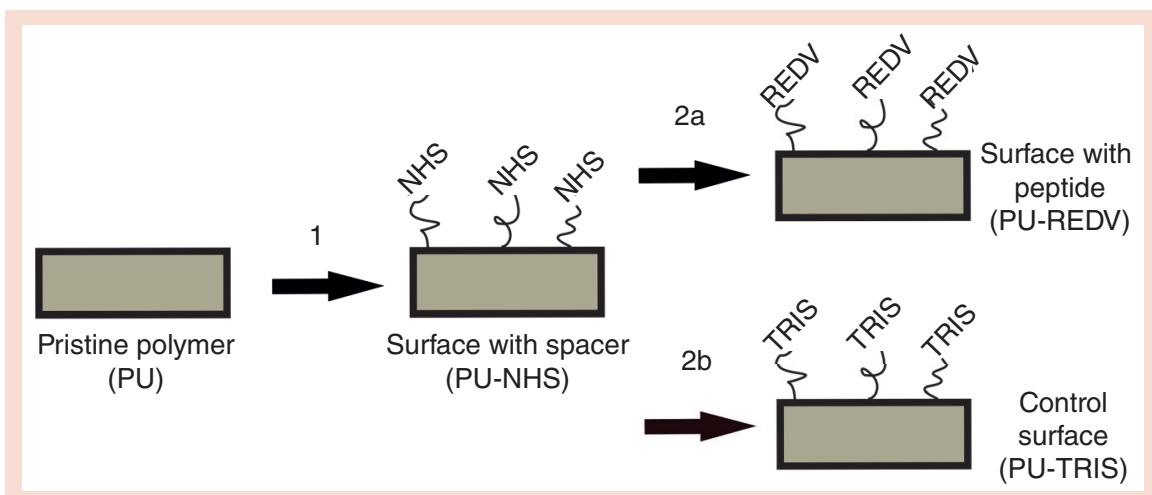

Figure 1. Scheme presenting types of materials used in the study.
PU discs modified with AA were placed in $0.05 \mathrm{M}$ 2-(N-morpholino)ethanesulfonic acid buffer (MES) for $1 \mathrm{~h}$. Then, samples were transferred to the $5 \mathrm{mM} \mathrm{N}$-hydroxysulfosuccinimide (sulfoNHS) and $2 \mathrm{mM}$ 1-Ethyl-3-(3-dimethylaminopropyl)carbodiimide (EDC) solution for $15 \mathrm{~min}$ at room temperature (RT) and washed with MES buffer. Samples after reaction with $A A$ and sulfoNHS/EDC were marked as 'PU-NHS'.

In the next step, discs were placed in the GSGREDVGSG solution (5 mM) in $0.1 \mathrm{M}$ sodium phosphate buffer, $\mathrm{pH} 8.0$ for $4 \mathrm{~h}$ at RT. Next, discs were incubated in sodium phosphate buffer, $\mathrm{pH}=9$ for $1 \mathrm{~h}$ to hydrolyze unreacted sulfoNHS groups. Finally, samples were rinsed with PBS. Samples after reaction with peptide were marked as 'PU-REDV'.

Simultaneously to the peptide immobilization, control samples were prepared. After reaction with sulfoNHS and EDC, discs were placed in tris(hydroxymethyl)aminomethane (TRIS) solution $(5 \mathrm{mM})$ in $0.1 \mathrm{M}$ sodium phosphate buffer, pH 8.0, for $4 \mathrm{~h}$ at RT, which should lead to TRIS conjugation due to the amide bond formation. Afterward, discs were incubated in sodium phosphate buffer, $\mathrm{pH}=9$ for $1 \mathrm{~h}$ to hydrolyze unreacted sulfoNHS groups. Finally, samples were rinsed with PBS. Samples after reaction with TRIS were marked as 'PU-TRIS'.

Simultaneously, we analyzed samples chemically modified using different concentrations of the linker molecule (1, 2, 3 and 5\% $\mathrm{v} / \mathrm{v}$ of $\mathrm{AA}$ ) and peptide $(0.5,5 \mathrm{mM})$. A determination of the peptide containing the RGD sequence (5 mM, GSGRGDGSG, custom made, Novazym) was also carried out. The RGD grafting procedure was analogous to that described above for REDV grafting.

All analyzed samples in the form of discs (with a diameter of $10 \mathrm{~mm}$ ) were placed in a 24-well plate and contacted with BCA 


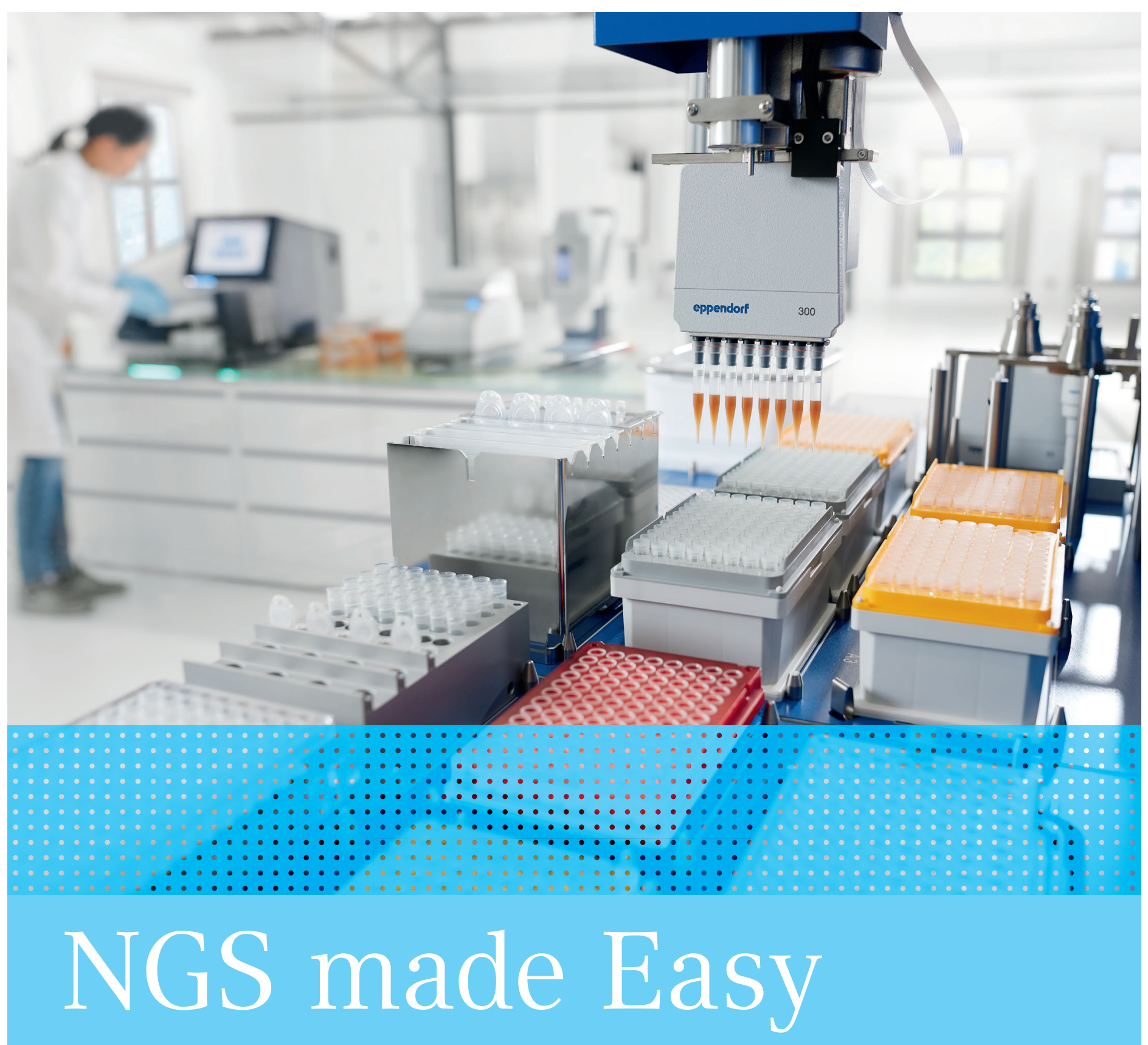

Optimize your NGS library preparation with the epMotion ${ }^{8}$

Next-generation sequencing sample

prep is a labor-intensive process, which requires experience, precision and accuracy to generate high-quality NGS libraries. The epMotion can automate your NGS library prep and eliminate the risk of pipetting errors, for reproducible results, and increased productivity.
$>$ Vast list of qualified NGS kit methods for easy implementation and high-quality NGS libraries

$>$ High accuracy from $200 \mathrm{~nL}-1,000 \mu \mathrm{L}$ $>$ UV light and HEPA air filter option

$>$ Intelligent tools selection shortens

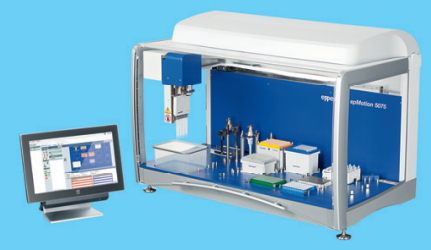
run times

$>$ Email notification of run status 
reagent (500 $\mu$ l per sample, $\left.1 \mathrm{~h}, 60^{\circ} \mathrm{C}\right)$. After the reaction, $\mathrm{BCA}$ solutions were cooled down to room temperature and transferred to a 96-well plate. The absorbance at $562 \mathrm{~nm}$ was red; BCA reagent was used as a blank.

The surface density of the grafted peptide was calculated as follows. The net absorbance used to calculate peptide amount was obtained by subtracting the absorbance value for PU-NHS from the value for PU-REDV. Next, the amount of peptide adsorbed on the sample's surface was calculated based on the standard curve equation ( $y=-0.012 \times 2+0.170)$ obtained for the same incubation conditions $(1 \mathrm{~h}$, $60^{\circ} \mathrm{C}$ ). Finally, the surface density of the adsorbed peptide was calculated as a number of peptide moles divided by the sample's surface.

\section{Statistical analysis}

Results of BCA analysis were expressed as mean $\pm \mathrm{SD}$. Statistical significance of differences was analyzed using single factor analysis of variance (ANOVA) for $\mathrm{p}<0.05$ with post-hoc Tukey's test (OriginPRO 8.0).

\section{Results \& discussion}

Influence of BCA reaction conditions The calibration curve for analyzed peptide (GSGREDVGSG) was prepared under conditions differing in IT and T. The aim of this experiment was to select incubation parameters that give relatively high absorbance values. The obtained curves for four different incubation conditions are presented in Figure 2. The absorbance values obtained for a given concentration of the peptide increased together with an increase in both IT and T. The smallest absorbance values were obtained for $\mathrm{IT}=37^{\circ} \mathrm{C}, \mathrm{T}=2 \mathrm{~h}$, whereas the absorbance values obtained for $\mathrm{IT}=60^{\circ} \mathrm{C}, \mathrm{T}=2 \mathrm{~h}$ were the highest.

Smith et al. suggested that during the BCA assay, the BCA-Cu ${ }^{1+}$ purple-blue complex is produced by two separate reactions [8]. The first one is temperatureindependent and it is based on oxidation of cysteine, cystine, tyrozine and tryptophan. In the second mechanism, which is temperature-dependent, $\mathrm{Cu}^{1+}$ is produced as a result of peptide bond oxidation. This process is more effective in higher temperatures $\left(60^{\circ} \mathrm{C}\right)$. The analyzed amino acid chain (GSGREDVGSG) does not involve any of the $\mathrm{Cu}^{2+}$-reducing amino acids. Thus, the reaction occurs only due to the presence of a peptide bond and, in our opinion, should be performed at higher temperatures. The obtained standard curves showed that the absorbance values were in fact higher at the higher incubation temperature. This finding was also in line with data obtained by other authors $[8,20]$. Taking into account these results and optimization of experiment time, we decided to perform all BCA assays under the followed conditions: $I T=60^{\circ} \mathrm{C}$, $\mathrm{T}=1 \mathrm{~h}$.
Another aspect that should be considered is the linearity of standard curves. According to the information from the supplier, peptide concentrations in the range 0.5 to $30 \mu \mathrm{g} / \mathrm{ml}$ give a linear response with absorption. Surprisingly, in the case of the GSGREDVGSG peptide, the polynomial curve (Figure 2B) gave better fit of the absorption values than the linear curve (Figure 2A). Smith et al. [8] showed that the linearity of standard curves in the BCA test strongly depends on the type of protein

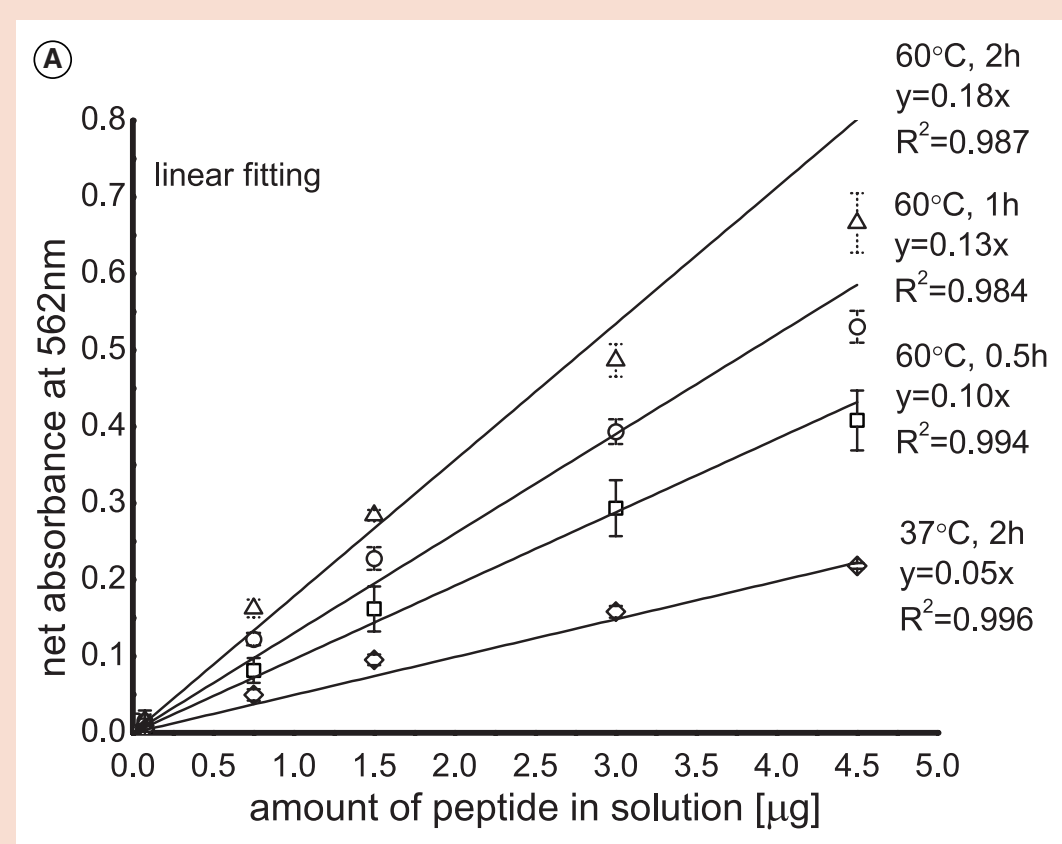

(B)

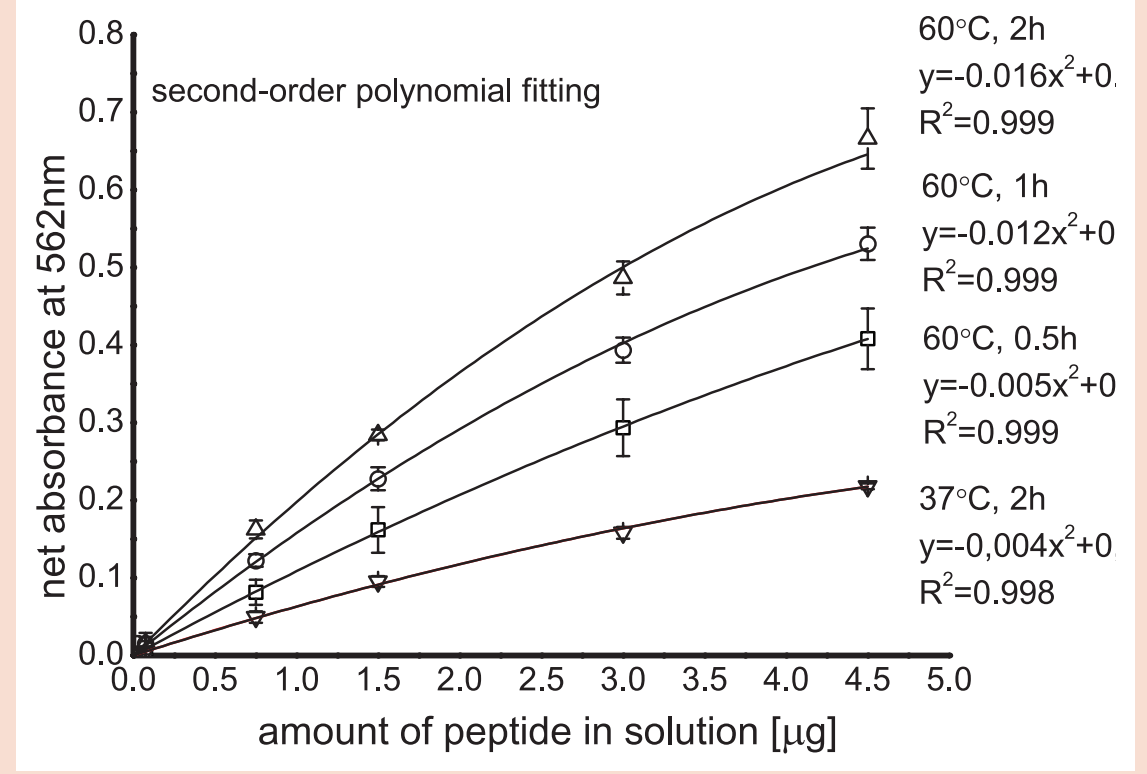

Figure 2. Standard curves resulting from the reaction of GSGREDVGSG with BCA reagent under different incubation time and temperatures. (A) Linear fitting; B) second-order polynomial fitting; data are presented as $\mathrm{MV} \pm \mathrm{SD}(\mathrm{n}=8)$. 


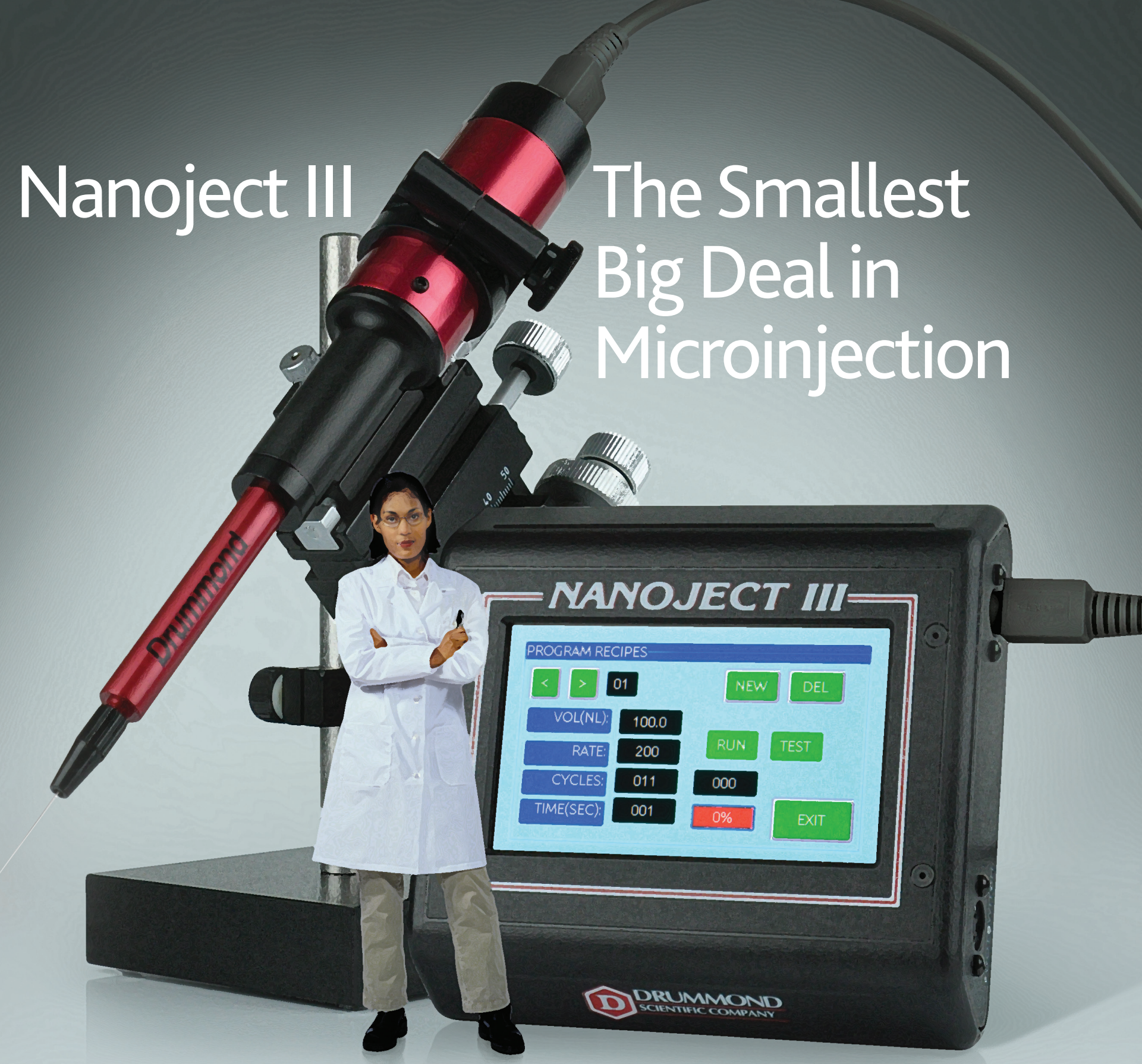

Completely programmable nanoliter injection control expands your capabilities

- User-friendly touchscreen setup for single injections as well as multiple injection cycle recipes

- Advanced hydraulics deliver precise, consistent injection volumes down to 0.6 nanoliters

- Improved chuck design provides simple, secure micropipet attachment without the need for O-rings

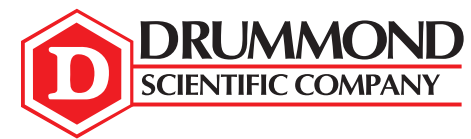

Developers of the original Pipet-Aid
Go to injection.expert for more details about Nanoject III expanded microinjection capabilities.

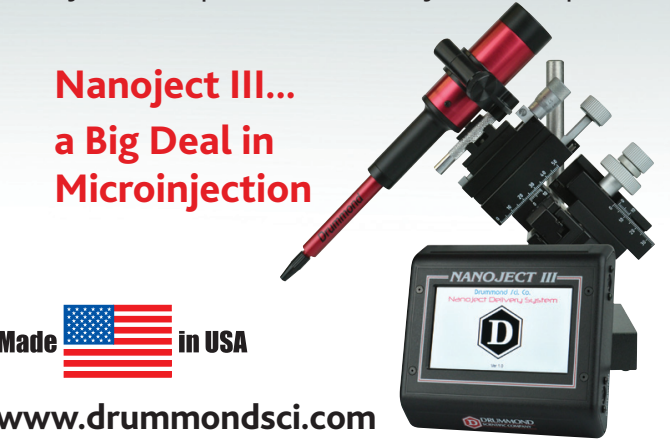

www.drummondsci.com

500 Parkway, Box 700 • Broomall, PA 19008 • 800.523 .7480 
being analyzed and on the incubation parameters. In the case of GSGREDVGSG all curves presented a slightly parabolic shape. The standard curves became less linear at higher incubation temperatures and longer incubation times. Based on these findings, we considered $\mathrm{IT}=60^{\circ} \mathrm{C}$ and $\mathrm{T}=1 \mathrm{~h}$ to be the optimal incubation parameters. These results remain in accordance with the studies by Tylianakis et al. [21]. They proved that many solid-supported substances required $1 \mathrm{~h}$ of incubation at $60^{\circ} \mathrm{C}$ to reach plateau absorbance values.

\section{Influence of polymer substrate}

As already mentioned, the purpose of the presented work was to estimate the surface density of a peptide chemically bound to a PU substrate. First, we aimed to check if the base material $(\mathrm{PU})$ interferes with the BCA reagent. Wiechelman et al. showed there is a number of substances containing functional groups similar to those present in cysteine, cystine, tryptophan and tyrosine that react with the BCA reagent [20]. In the case of PU, the positive result during BCA assay might come from (i) polyurethane bonds; (ii) the solvent used during processing granulate into film; and (iii) chemical residues present on the surface/inside the granules supplied from the manufacturer.
To verify these hypotheses, a number of tests were carried out. The BCA reagent was first contacted with a chemically unmodified PU film. The results showed that the material had reacted with BCA and gave a positive response. The list of interfering substances provided by the PU manufacturer indicates that DMAc interferes with BCA. Thus, the possibility of DMAc residues remaining in the materials was verified. For this purpose, materials were dried in various conditions. DMAc is a low volatile solvent (boiling point $=165^{\circ} \mathrm{C}$ under normal pressure), and therefore drying under low pressure was used to increase the efficiency of the drying process. Namely, the following drying conditions were applied: drying in $40^{\circ} \mathrm{C}$ under normal pressure (40); drying in $40^{\circ} \mathrm{C}$ under normal pressure followed by drying under low pressure (40L); drying in $70^{\circ} \mathrm{C}$ under normal pressure followed by drying under low pressure (70L); and drying in $100^{\circ} \mathrm{C}$ under normal pressure followed by drying under low pressure (100L).

The obtained results are presented in Figure 3. In each PU sample, the obtained absorbance value was higher than the absorbance value for blank ( $p<0.05)$. At the same time, the values were similar for all PU samples dried under different temperatures and pressures ( $p>0.05)$. On this basis,

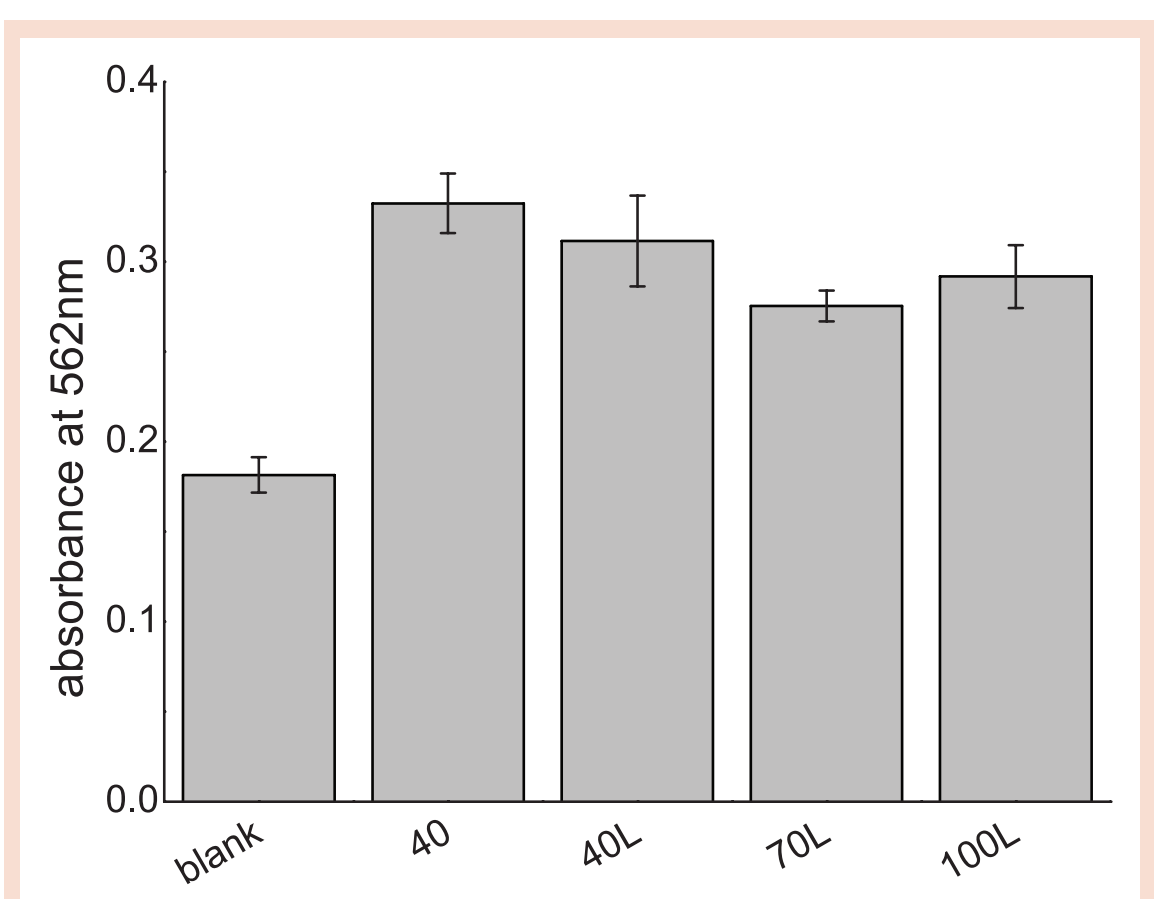

Figure 3. Results of BCA assay obtained for pristine polyurethane dried under different conditions. Drying in $40^{\circ} \mathrm{C}$ under normal pressure $(40)$, drying in $40^{\circ} \mathrm{C}$ under normal pressure followed by drying under low pressure $(40 \mathrm{~L})$, drying in $70^{\circ} \mathrm{C}$ under normal pressure followed by drying under low pressure $(70 \mathrm{~L})$, drying in $100^{\circ} \mathrm{C}$ under normal pressure followed by drying under low pressure (100L); data are presented as $M V \pm S D(n=8)$ we concluded that the solvent has been successfully removed from the polymer and the positive BCA test response was not derived from DMAc.

Another potential BCA interfering factor may be the urethane bond. The structure of this bond is similar to the peptide bond. However, the BCA test carried out with pure PU granulate gave a negative result (Figure 4). A similar result was obtained for three different types of PU; OD560 values were comparable to the values of a blank. On this basis, we concluded that the polyurethane bond was not an interfering agent.

As a next step, the hypothesis regarding the presence of chemical residues inside the PU granules was verified. Such residues may diffuse to the surface of the film in the process of dissolving and processing granules and cause a positive material response during the BCA test. The results showed a significant increase $(p<0.05)$ in the absorbance value for BCA contacted with cut granules (Figure 4). The OD560 value was significantly higher compared with whole (non-cut) granules. What is more, OD560 values depended on the type of PU analyzed. On this basis, we concluded that the positive response of the PU foil during BCA assay is the result of the presence of chemical additives used in the granule production process.

\section{Density of peptide chemically grafted to PU}

To assess the surface density of the peptide, a number of materials were prepared and incubated with BCA reagent. As the control material, the unmodified PU film was reused (PU). The analyzed material was a PU film with a chemically attached peptide GSGREDVGSG (PU-REDV). The modification process was performed in several stages: (i) activation of the material; (ii) attachment of the spacer molecule terminated with carboxylic groups; (iii) activation of carboxyl groups with the use of sulfoNHS/EDC; and (iv) reaction with the peptide. The experiment also applied two reference materials. The first one (PU-NHS) was subjected to subsequent modification stages (1-3) but omitting the last stage - peptide attachment (4). The second reference material (PU-TRIS) was subjected to subsequent modification stages (1-3), and in the last stage a control molecule (TRIS) was attached to the surface of the material. The material modification 


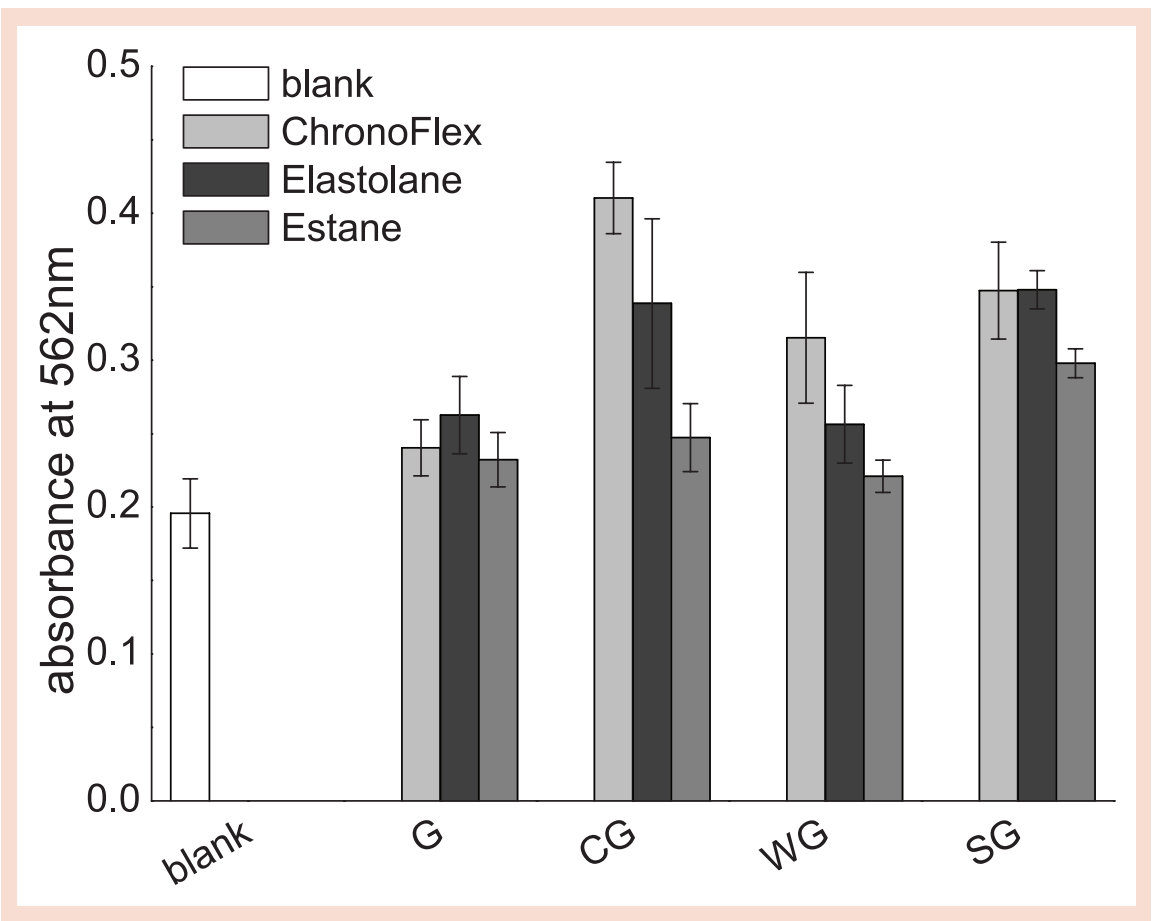

Figure 4. Results of BCA assay obtained for pristine polyurethane of different types and different forms. Granules $(G)$, cut granules $(C G)$, granules washed with alcohol $(W G)$, granules cleaned with scalpel $(\mathrm{SG})$; data are presented as $\mathrm{MV} \pm \mathrm{SD}(\mathrm{n}=8)$.

scheme is presented in Figure 1. As can be seen, all modified materials were contacted with sulfoNHS in order to attach peptide/ control molecule. Vashist et al. showed that
sulfoNHS interferes with BCA assay [22]. To remove any unreacted sulfoNHS groups from the surface of the material, all tested materials were hydrolyzed $(1 \mathrm{~h}, \mathrm{pH}=9)$

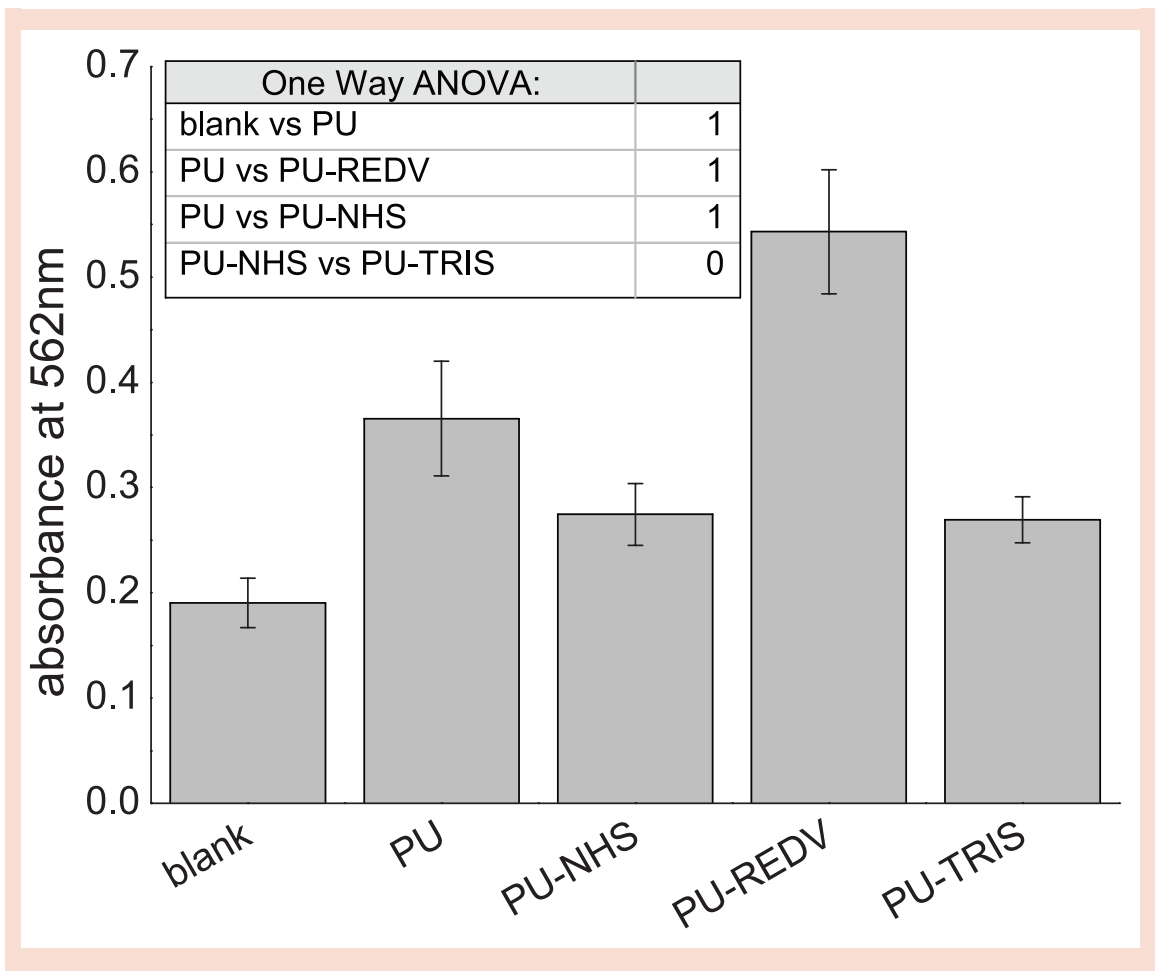

Figure 5. Results of BCA assay obtained for non-modified polyurethane (PU), polyurethane modified with peptide (PU-REDV) and control materials (PU-NHS, PU-TRIS). Data are presented as MV \pm SD $(n=8)$.

ANOVA: Analysis of variance. before the BCA test. According to the literature, the half-life of sulfoNHS is only a few minutes at $\mathrm{pH}>8$ [23].

The results of the BCA assay obtained for nonmodified PU as well as the results for PU with chemically grafted peptide (PU-REDV) are presented in Figure 5. Pristine PU (PU) reacted with $\mathrm{BCA}$ reagent, giving the absorbance value of OD562 =0.365. After the first step of modification absorbance decreased and reached the value of 0.274 (PU-NHS). The difference between absorbance values for PU and PU-NHS was statistically significant $(p<0.05)$. On the other hand, the value obtained for PU-NHS was comparable to the absorbance value of blank. This indicates that (1) the process of hydrolysis was effective and the unreacted sulfoNHS groups were absent on the material; and (2) the interfering substance that was present on the surface of the PU film was covered by the modification layer. Such a material can be successfully used as a reference material in the assessment of the peptide surface density. In this case, the peptide surface density is directly proportional to the absorbance value subtracting the background value (the absorbance value obtained for PU-NHS).

As expected, after coupling the peptide (PU-REDV) the absorbance value increased to the highest value compared with other tested materials (OD562 $=0.543$ ). On this basis, it can be concluded that the reaction of peptide grafting was successful. Incubation of the BCA reagent with control material (PU-TRIS) generated a lower absorbance value, comparable to the value obtained for PU-NHS (OD562 = 0.269 ; $p>0.05$ vs PU-NHS).

Figure 6 presents the results obtained for various densities of surface-grafted peptide. The final surface density of the grafted peptide is influenced by both the concentration of the linker molecule solution as well as the concentration of the peptide solution. In the study, we used four different concentrations of the linker and two different concentrations of peptide, resulting in eight different surface densities of the peptide. PU-NHS and PU-TRIS were used as control materials.

As expected, all control materials generated similar absorbance values (for all tests AA concentration). As can be seen in the Figure 6, the absorbance values obtained for materials modified with 3 and 5\% AA were significantly higher than those of the control materials. In the case of 1 


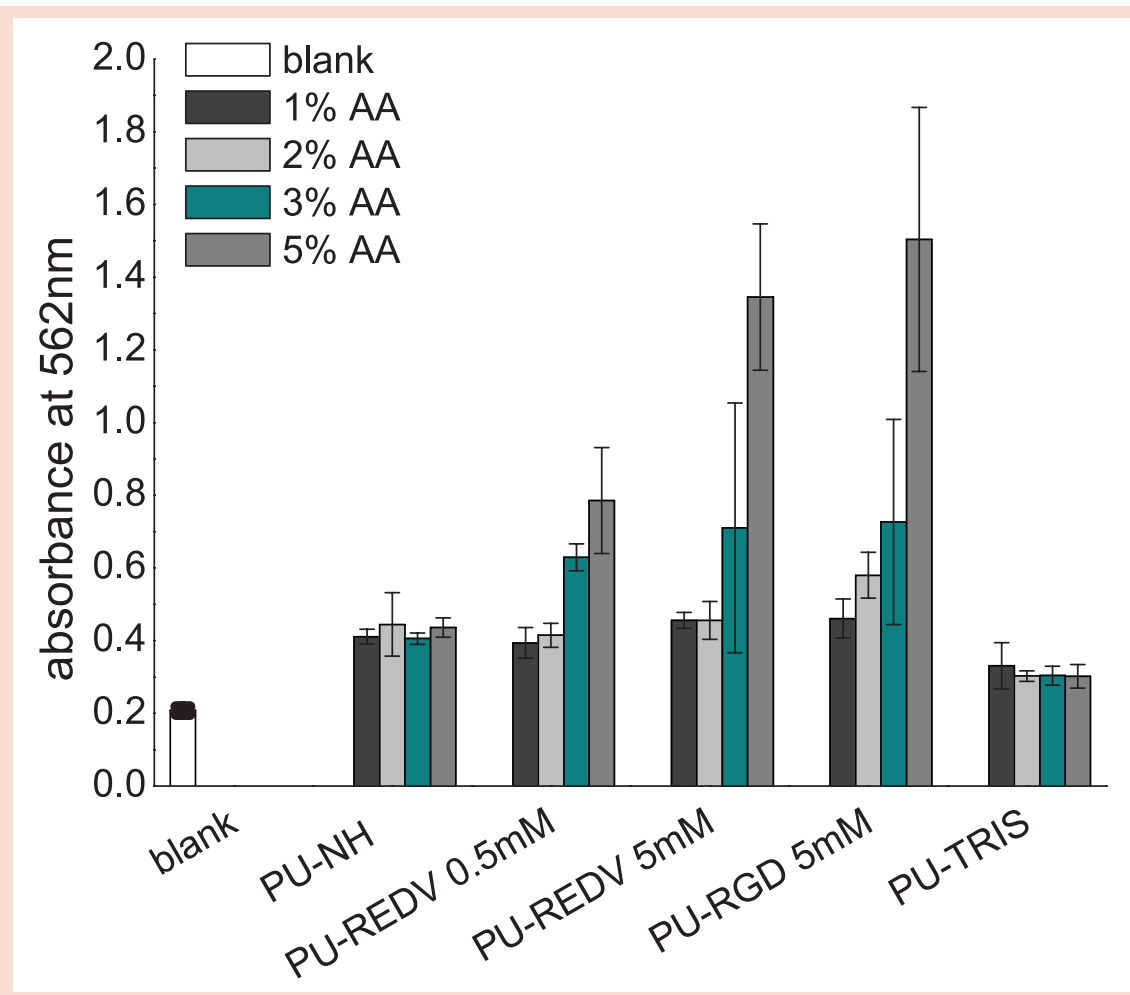

Figure 6. Results of BCA assay obtained for materials differ in surface density and type of grafted peptide. PU-REDV $0.5 \mathrm{mM}$ - materials modified with $0.5 \mathrm{mM}$ solution of GSGREDVGSG, PU-REDV $5 \mathrm{mM}$ - materials modified with $5 \mathrm{mM}$ solution of GSGREDVGSG, PU-RGD $5 \mathrm{mM}$ - materials modified with $5 \mathrm{mM}$ solution of GSGRGDGSG, control materials: (PU-NHS, PU-TRIS). Data are presented as $M V \pm S D(n=8)$ and $2 \%$ AA the resulting peptide surface densities were too low to be determined (values comparable to those obtained for PU-NHS). These results were observed for both PU-REDV and PU-RGD.

When determining the surface density of a peptide, the response obtained for the reference material should be taken into account. In our case, the reference material presented the same surface structure, only without the peptide (PU-NHS). The OD560 value obtained for PU-NHS was subtracted from the OD560 value obtained for PU-REDV/PU-RGD and then the surface density was determined using a standard curve. The values of peptide surface density calculated for various materials are presented in Table 1. The applied method allowed the peptide density in the range of 1.2 to $5.7 \mathrm{nmol} / \mathrm{cm}^{2}$ to be determined. It has been shown that this density is sufficient to induce a biological response. What is important, a specific biological response of a cell is highly correlated with an optimal peptide surface density. Therefore, in our opinion, the development of a fast, simple and effective technique measuring the surface density of solid-supported peptides is crucial in the study of bioactive materials.

As a result of the conducted studies, we concluded that polymer substrate (PU) might interfere with the BCA reagent. The interfering agents are probably the chemical additives used in the specific type of PU's granule production process, while the polyurethane bond itself is not an interfering agent.

Studies have also shown that drying conditions applied during processing of PU samples did not influence the assay
Table 1. Density of surface-grafted peptide $\left(\mathrm{nmol} / \mathrm{cm}^{2}\right)$ for different concentration of linker molecule (AA) and peptide. Data are presented as MV \pm SD $(n=8)$.

\begin{tabular}{|l|l|l|l|l|}
\cline { 2 - 6 } & \multicolumn{5}{c}{ AA (\%) } \\
\cline { 2 - 6 } & $\mathbf{1}$ & $\mathbf{2}$ & $\mathbf{3}$ & \\
\hline PU-REDV 0.5 mM & $\mathrm{n} / \mathrm{a}$ & $\mathrm{n} / \mathrm{a}$ & $1.6 \pm 0.2$ & $1.9 \pm 0.8$ \\
\hline PU-REDV 5 mM & $\mathrm{n} / \mathrm{a}$ & $\mathrm{n} / \mathrm{a}$ & $1.7 \pm 1.8$ & $4.8 \pm 1.1$ \\
\hline PU-RGD 5 mM & $\mathrm{n} / \mathrm{a}$ & $5.7 \pm 1.9$ \\
\hline
\end{tabular}

response. To summarize, surface density of REDV peptide chemically grafted to PU can be determined; however, the appropriate control material must be chosen with great care (Table 1).

\section{Author contributions}

BBR: the conception and design of the study, analysis and interpretation of data, drafting the article; AK: performing all experiments, analysis and interpretation of data, drafting the article.

\section{Financial \& competing interests disclosure}

This work was supported by the National Centre for Research and Development under the Poland-Taiwan Cooperation. The authors have no other relevant affiliations or financial involvement with any organization or entity with a financial interest in or financial conflict with the subject matter or materials discussed in the manuscript apart from those disclosed.

No writing assistance was utilized in the production of this manuscript.

\section{Open access}

This work is licensed under the Creative Commons Attribution 4.0 License. To view a copy of this license, visit http://creativecommons.org/licenses/by/4.0/

\section{Supplementary data}

To view the supplementary data that accompany this paper please visit the journal website at: www.future-science. com/doi/suppl/10.2144/btn-2018-0004

\section{References}

1. John CM, Odom RW, Salvati L et al. XPS and TOF-SIMS microanalysis of a peptide/polymer drug delivery device. Anal. Chem. 67(21), 38713878 (1995).

2. Apte JS, Collier G, Latour RA, Gamble LJ, Castner DG. XPS and ToF-SIMS investigation of alpha-helical and beta-strand peptide adsorption onto SAMs. Langmuir 26(5), 3423-3432 (2010).

3. Neff JA, Tresco PA, Caldwell KD. Surface modification for controlled studies of cell-ligand interactions. Biomaterials 20(23-24), 2377-2393 1999.

4. Guicai L, Xiaoli S, Ping Y, Ansha Z, Nan H. Investigation of fibrinogen adsorption on solid surface by quartz crystal microbalance with dissipation (QCM-D) and ELISA. Solid State lonics 179(2126), 932-935 (2008). 
5. Tzoneva R, Heuchel M, Groth T et al. Fibrinogen adsorption and platelet interactions on polymer membranes. J. Biomater. Sci. Polym. Ed. 13(9), 1033-1050 (2002).

6. Causa F, Battista E, Della Moglie R et al. Surface investigation on biomimetic materials to control cell adhesion: the case of RGD conjugation on PCL. Langmuir 26(12), 9875-9884 (2010).

7. Sapan CV, Lundblad RL, Price NC. Colorimetric protein assay techniques. Biotechnol. Appl. Biochem. 29(Pt 2), 99-108 (1999).

8. Smith PK, Krohn RI, Hemranson GT et al. Measurement of protein using bicinchoninic acid. Anal. Biochem. (150), 76-85 (1985).

9. Brown RE, Jarvis KL, Hyland KJ. Protein measurement using bicinchoninic acid: elimination of interfering substances. Anal. Biochem. 180(1), 136-139 (1989).

10. Schoel B, Welzel M, Kaufmann SHE. Quantification of protein in dilute and complex samples: modification of the bicinchoninic acid assay. J. Biochem. Biophys. Methods 30(2-3), 199-206 (1995).

11. Noble JE, Bailey MJA. Chapter 8. In: Quantitation of Protein, 1st Ed. 463, Elsevier Inc. (2009).

12. Gloria A, Causa F, Russo T et al. Three-dimensional poly(E-caprolactone) bioactive scaffolds with controlled structural and surface properties. Biomacromolecules 13(11), 3510-3521 (2012).
13. Tyllianakis PE, Kakabakos SE, Evangelatos GP, Ithakissios DS. Direct colorimetric determination of solid-supported functional groups and ligands using bicinchoninic acid. Anal. Biochem. 219(2), 335-340 (1994).

14. Krohn RI. The colorimetric detection and quantitation of total protein. Curr. Protoc. Cell Biol. (Suppl. 52), 1-28 (2011).

15. Ceylan H, Tekinay AB, Guler MO. Selective adhesion and growth of vascular endothelial cells on bioactive peptide nanofiber functionalized stainless steel surface. Biomaterials 32(34), 8797-8805 (2011).

16. Wei $Y$, Ji Y, Xiao L-L, Lin Q, Xu J, Ren K, Ji J. Surface engineering of cardiovascular stent with endothelial cell selectivity for in vivo re-endothelialisation. Biomaterials 34(11), 2588-2599 (2013).

17. Ji Y, Wei Y, Liu X, Wang J, Ren K, Ji J. Zwitterionic polycarboxybetaine coating functionalized with REDV peptide to improve selectivity for endothelial cells. J. Biomed. Mater. Res. 100 A, 1387-1397 (2012).

18. Wang W, Guo L, Yu Y, Chen Z, Zhou R, Yuan Z. Peptide REDV-modified polysaccharide hydrogel with endothelial cell selectivity for the promotion of angiogenesis. J. Biomed. Mater. Res. Part A 103, 1703-1712 (2015).

19. Butruk-Raszeja BA, Trzaskowska PA, Kuzminska A, Ciach T. Polyurethane modification with acrylic acid by $\mathrm{Ce}(\mathrm{IV})$-initiated graft polymer- ization. Open Chem. 14(1), (2016) doi:10.1515/ chem-2016-0020.

20. Wiechelman KJ, Braun RD, Fitzpatrick JD. Investigation of the bicinchoninic acid protein assay: Identification of the groups responsible for color formation. Anal. Biochem. 175(1), 231237 (1988)

21. Tyllianakis PE, Kakabakos SE, Evangelatos GP, Ithakissios DS. Direct colorimetric determination of solid-supported functional groups and ligands using bicinchoninic acid. Anal. Biochem. 219(2), 335-340 (1994).

22. Hermanson GT. Bioconjugate Techniques Academic Press (2008).

Received 7 February 2018; Accepted for publication: 25 April 2018

Address correspondence to: Beata A ButrukRaszeja, Laboratory of Biomedical Engineering, Faculty of Chemical \& Process Engineering, Warsaw University of Technology, Warynskiego 1, 00-645

Warsaw, Poland. E-mail: Beata.Raszeja@pw.edu.pl

\section{To purchase reprints of this article, contact} s.cavana@future-science.com

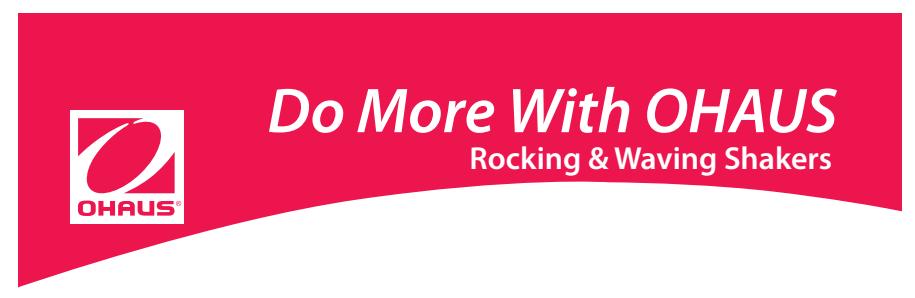

\section{Shake It Up With OHAUS}

With incubating and open air options, OHAUS rocking and waving shakers have the features you need for gene editing sample preparation applications. Designed to offer fast, reproducible results, OHAUS shakers offer adjustable tilt angles and digital control panels for optimum sample testing and preparation. Don't limit yourself to just measurement- Do More.

\section{Visit www.ohaus.com to learn more ont foul}
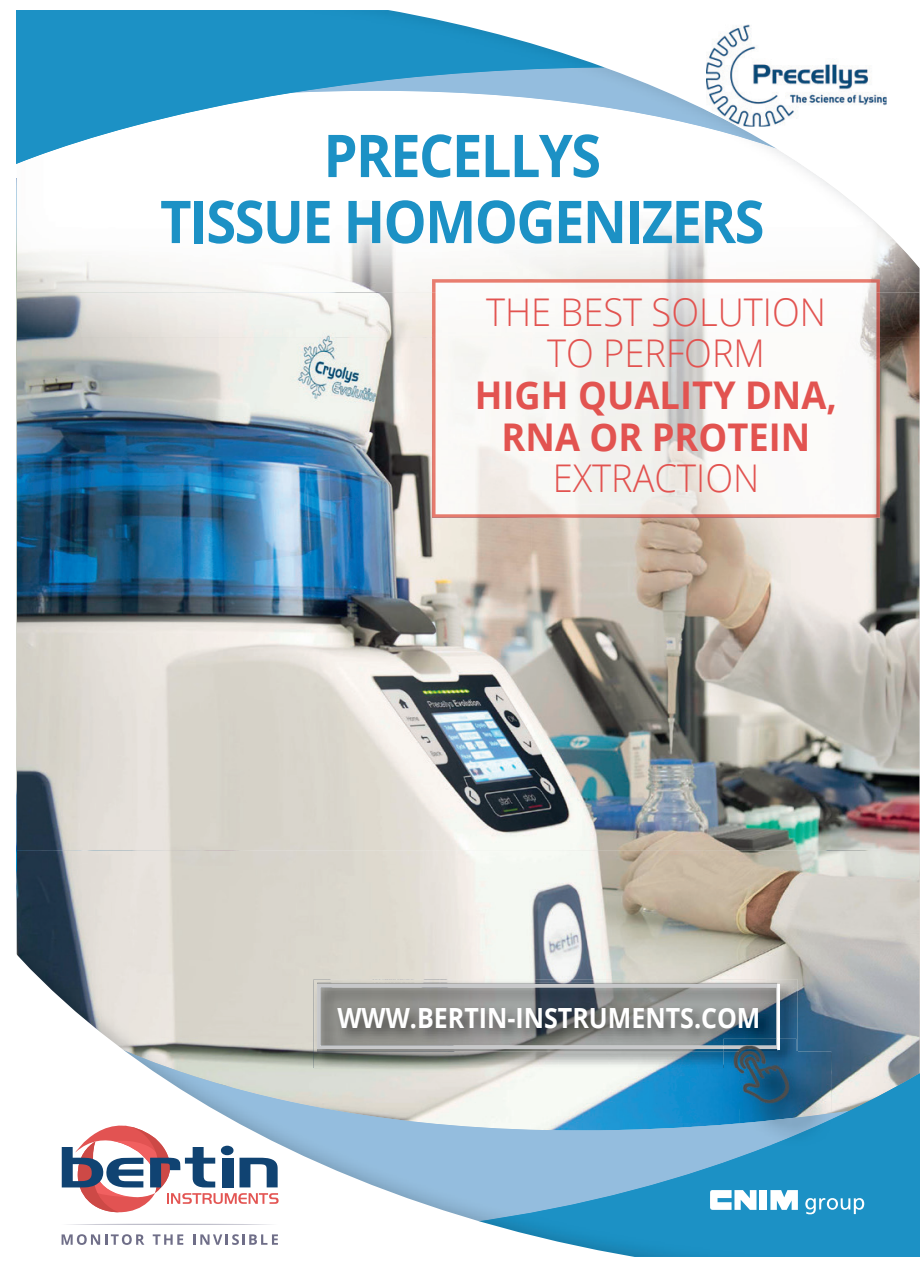